\title{
Association of fascin-1 with mortality, disease progression and metastasis in carcinomas: a systematic review and meta-analysis
}

Vanessa Y Tan ${ }^{1,2}$, Sarah J Lewis ${ }^{1}$, Josephine C Adams ${ }^{2 *}$ and Richard M Martin ${ }^{1 *}$

Please see related commentary article here http://www.biomedcentral.com/1741-7015/11/53

\begin{abstract}
Background: Fascin-1 is an actin-bundling protein expressed in many human carcinomas, although absent from most normal epithelia. Fascin-1 promotes filopodia formation, migration and invasion in carcinoma cells; in mouse xenograft tumor models it contributes to metastasis. Fascin-1 is an interesting candidate biomarker for aggressive, metastatic carcinomas but data from individual studies of human tumors have not yet been pooled systematically.

Methods: This systematic review was conducted in accordance with PRISMA guidelines, using fixed and random effects models, as appropriate, to undertake meta-analysis.

Results: A total of 26 immunohistochemical studies of 5 prevalent human carcinomas were identified for meta-analysis. Fascin-1 was associated with increased risk of mortality for breast (pooled hazard ratio, (HR) $=2.58$; $95 \%$ confidence interval $(\mathrm{Cl}) 1.48$ to $4.52 ; P=0.001)$, colorectal ( $\mathrm{HR}=1.60(1.37$ to $1.86 ; P<0.001)$ and esophageal carcinomas $(\mathrm{HR}=1.35$; $\mathrm{Cl} 1.13$ to $1.60 ; P=0.001)$. There was no evidence of association of fascin-1 with mortality in gastric and lung carcinomas. Fascin-1 was associated with increased risk of disease progression in breast ( $\mathrm{HR}=2.48 ; \mathrm{Cl} 1.38$ to 4.46; $P=0.002)$ and colorectal carcinomas ( $H R=2.12 ; \mathrm{Cl} 1.00$ to $4.47 ; P=0.05)$, but not with progression of lung carcinomas $(\mathrm{HR}=0.95 ; \mathrm{Cl} 0.49$ to $1.85 ; P=0.9)$. Fascin-1 was associated with increased risk of lymph node metastasis in colorectal (pooled risk ratio $(\mathrm{RR})=1.47 ; \mathrm{Cl} 1.26$ to $1.71 ; P<0.001$ ) and gastric carcinomas $(\mathrm{RR}=1.43 ; \mathrm{Cl} 1.21$ to $1.70 ; P<0.001)$. There was no evidence of association of fascin-1 with lymph node metastasis in lung or esophageal carcinomas. Fascin-1 was associated with increased risk of distant metastasis in colorectal ( $R R=1.70 ; \mathrm{Cl} 1.18$ to $2.45 ; P=0.004)$ and gastric carcinomas ( $R R=1.93 ; \mathrm{Cl} 1.21$ to $3.33 ; P=0.02$ ). No association with distant metastasis in esophageal carcinomas was observed. Pooling across all the carcinomas provided strong evidence for association of fascin-1 with increased risk of mortality ( $\mathrm{HR}=1.44 ; \mathrm{Cl} 1.24$ to $1.68 ; P<0.001 ; \mathrm{n}=3,645)$, lymph node metastasis ( $\mathrm{RR}=1.36 ; \mathrm{Cl} 1.18$ to $1.55 ; P<0.001$; $\mathrm{n}=2,906)$ and distant metastasis $(1.76 ; 1.34$ to $2.32 ; P<0.001 ; \mathrm{n}=1,514)$.
\end{abstract}

Conclusions: Fascin-1 is associated consistently with increased risk of mortality in breast, colorectal and esophageal carcinomas and with metastasis in colorectal and gastric carcinomas. The results were stable to various sensitivity analyses and did not vary by predefined subgroups. These data will assist rational decision making for focusing investigations of fascin-1 as a biomarker or therapeutic target onto the most relevant carcinomas.

Keywords: Fascin-1, carcinoma, mortality, metastasis, meta-analysis

\footnotetext{
* Correspondence: jo.adams@bristol.ac.uk; Richard.Martin@bristol.ac.uk

'School of Social and Community Medicine, University of Bristol, 39 Whatley

Road, Bristol BS8 2PS, UK

${ }^{2}$ School of Biochemistry, University of Bristol, Medical Sciences Building,

University Walk, Bristol BS8 1TD, UK

Full list of author information is available at the end of the article
} 


\section{Background}

Biomarkers have a pivotal role in cancer screening, diagnosis, prognosis and therapeutic monitoring. Since tumor metastasis remains a major cause of cancer mortality, there is a compelling need for the discovery and validation of novel biomarkers for early characterization of carcinomas by their aggressive potential [1].

Over the last 10 years, in vitro, in vivo and clinical immunohistochemical studies have implicated fascin-1 as a novel candidate biomarker for aggressive carcinomas of the biliary duct, bladder, brain, breast, colorectum, endometrium, kidney, liver, lung, neck, esophagus, pharynx, ovary, pancreas, prostate and stomach [2-4]. Fascin-1 is a $55-\mathrm{kDa}$, actin-bundling protein that plays a key role in the assembly and stability of cell protrusions and other actinbased structures that aid in cell motility, migration and invasion $[2,4]$. In normal epithelia, fascin-1 is usually absent or present at low levels, yet its expression is increased in colorectal adenomas, esophageal dysplasia and in many carcinomas [2-8]. Fascin-1 increases the migratory capacity of carcinoma cells in culture [9-12]; this is associated with increased invasive and metastatic potential in mouse tumor xenograft models [10-13]. These effects are considered to underlie the observed correlation between fascin-1 expression and clinical aggressiveness in human carcinomas [2-4]. Fascin-1 was recently implicated as the binding partner of the metastasis inhibitory small molecule, macroketone, and this has further increased interest in its potential as a therapeutic target $[13,14]$.

Given the temporal and financial commitments needed to translate basic research to the clinic, it is important to evaluate candidate biomarkers or targets thoroughly at an early stage. Several studies [13,15-17] have investigated the clinical relevance of fascin-1 mRNA levels in tumor tissues. For breast carcinomas, it was reported that high fascin-1 mRNA levels were associated with a lung metastasis signature [16] and decreased overall and metastasis- free survival [13]. However, tissue mRNA is not well-suited to examine the expression of fascin-1 in tumors, because the extracted mRNAs derive from a mixture of cells including myofibroblasts, endothelial cells and dendritic cells that express fascin-1 constitutively [18]. Many immunohistochemical studies of fascin-1 protein in carcinomas have been published. The majority of these immunohistochemical studies have correlated fascin-1 protein in the primary tumor with poor prognosis; however, it is not yet clear if fascin-1 has independent value as a biomarker as the individual studies are not always consistent. For example, immunohistochemical studies of breast carcinomas have reached discrepant conclusions on its association with mortality and metastasis [19-22]. Immunohistochemistry is a complex metric for meta-analysis, due to the use of different scoring systems to assess the extent of fascin-1 staining in tumor specimens, yet studies of fascin- 1 have the advantage that almost all publications to date have used the same two antibodies to fascin-1.

To evaluate the hypothesis that fascin-1 can serve as an early marker for identification of the most aggressive carcinomas with metastatic potential, we have conducted a systematic review and meta-analysis of studies that have investigated the clinical implication of fascin-1 in carcinoma progression and patient mortality by immunohistochemistry.

\section{Methods}

\section{Inclusion and exclusion criteria}

A systematic review of all published literature on the association of fascin-1 protein expression with carcinoma progression in breast, colorectal, gastric, lung and esophageal carcinomas was carried out. We focused on these carcinomas because they are the most prevalent carcinomas that are major sources of morbidity and mortality worldwide [23].

Studies had to meet the following inclusion criteria: (1), either randomized controlled trials, cohort or casecontrol studies; (2), in humans with carcinomas of the breast, colorectum, stomach, lung or esophagus; (3), detected fascin-1 by immunohistochemistry and compared high versus low fascin-1 staining; negative versus positive fascin-1 staining; or negative, low and high fascin1 staining, and, (4), reported data for at least one of the following outcomes: lymph-node or distal metastasis, disease progression or mortality. We excluded studies investigating tissue mRNA because the extracted mRNAs derive from a mixture of cells including myofibroblasts, endothelial cells and dendritic cells that express fascin- 1 constitutively [18]. We excluded case reports, animal and in vitro studies.

\section{Data sources}

We searched the Medline, Embase, Web of Science and PubMed bibliographic databases from their inception until April 2012, using a combined text word and MeSH heading search strategy (see Additional file 1 for search terms). We also searched the reference lists of relevant articles and reviews [2-4]. We did not contact any organizations to obtain unpublished results and we did not identify any on-going studies from our systematic review. Authors of conference abstracts were contacted for the published report. We did not apply any language restrictions.

\section{Selection of studies}

The title and abstracts of all retrieved papers were then assessed using the pre-specified inclusion criteria by one author (VYT). Where abstracts were not available or when eligibility was unclear based on the abstract, the full papers were obtained and assessed. Some studies were excluded on the basis of the title or abstract; for all 
others, full papers were obtained and reviewed by two independent assessors (VYT, RMM), with each assessor blind to the decision of the other. Discrepancies in assigning studies as eligible were resolved by mutual agreement and discussion with JCA. We identified duplicate publications by reviewing study name, authors, location, study population, dates and study design. For multiple study publications from the same patient cohort reporting on similar outcomes, we chose the study with the largest number of cases. For studies that presented different outcomes, we extracted outcomes from both publications.

\section{Data extraction}

Data were extracted onto standardized pro forma by one assessor (VYT) and then double-checked by two others (RMM and SJL). Data were extracted on year of publication, study size, mean or median age of patients, location and study design. Different semi-quantitative parameters were used to categorize and dichotomize fascin-1 staining (see Additional file 1 for alternative categorization methods used to assess immunohistochemical staining of fascin-1). Data were extracted on fascin-1 scoring and categorization, the total number of patients in each fascin-1 category and total number of patients experiencing each outcome by fascin-1 category.

For dichotomous outcomes (that is, lymph node metastasis and distant metastasis), the number of patients with the event of interest and total number of patients in each category group (that is, high, low, positive or negative expression) were extracted and the data used to compute risk ratios. If separate data for immunoreactivity or intensity scores were given, we chose to extract the immunoreactivity scores. This is because a recent study [24] showed that immunoreactivity scores alone are a sufficient measure for estimating the association of fascin-1 with mortality. For time to event outcomes (that is, mortality and time-to-disease progression), a hazard ratio was extracted from the study report where possible, otherwise a hazard ratio was estimated from Kaplan Meier curves using the method of Tierney et al. [25] (described in Additional file 1). For data extracted from Kaplan-Meier curves, we attempted to check the result with the authors, as there is a potential to overestimate the true number of events [26]. For studies that did not provide a clear definition of their outcomes for time-todisease progression analysis, we assumed that disease progression was calculated from the date of surgery to the date of disease progression (which is a binary outcome indicating occurrence of mortality, recurrence or metastasis). For time-to-disease progression analysis, a positive hazard ratio (HR) implies an increased risk of disease progression. When a measure of effect (for example, hazard ratio) was adjusted for covariates, it was also extracted along with details of the corresponding covariates.

Where studies included results for each of normal tissue, precursor lesions and carcinomas, we extracted data on fascin-1 in the carcinomas only. For papers or conference abstracts where data were missing or not clear, authors were contacted requesting further information that would enable us to include their data in our metaanalysis. Any disagreements on values of data items extracted were resolved by discussion among VYT, RMM and JCA, or by attempting to contact the authors of the papers for clarification.

\section{Quality of studies}

The methodological quality of studies which presented mortality data was judged and agreed to by three assessors (RMM, SJL and VYT) using the Newcastle-Ottawa scale [27], which was developed to assess the quality of non-randomized cohort studies in meta-analysis. The studies are judged on three broad perspectives using a nine-point scale: the selection of the study group (0 to 4 points), comparability of cohorts ( 0 to 2 points) and ascertainment of outcome (0 to 3 points).

\section{Statistical analysis}

For our meta-analysis, we stratified the results by method of scoring (that is, low versus high or positive versus negative) and by type of carcinoma. We used the metan command in Stata (StataCorp. 2009. Stata Statistical Software: release 11.2. StataCorp LP; College Station, TX, USA) to calculate a summary hazard ratio (HR) for mortality and time-to-disease progression outcomes or a summary risk ratio (RR) for lymph node and distant metastasis outcomes. We combined fully adjusted effectestimates if these were available; otherwise, we used the unadjusted estimates.

Heterogeneity was assessed by performing Cochran's Q test. The $\mathrm{I}^{2}$ statistic was calculated as a quantitative measure of the degree of inconsistency across studies, where $0 \%$ indicates no heterogeneity and larger percentages indicate increasing heterogeneity [28]. For consistency of presentation throughout our paper, an $\mathrm{I}^{2}$ value of 0 is considered no heterogeneity, an $\mathrm{I}^{2}$ value of 1 to $25 \%$ is considered low heterogeneity, an $\mathrm{I}^{2}$ value of 25 to $75 \%$ is considered moderate heterogeneity and an $\mathrm{I}^{2}$ value of 75 to $100 \%$ is considered as high heterogeneity. We performed fixed-effects meta-analysis unless there was appreciable heterogeneity ( $\mathrm{I}^{2}$ value over $50 \%$ or chi-squared $P$-value less than 0.1 ), in which case we also performed a random-effects meta-analysis, which relaxes the assumption of a common treatment effect (that is, effect sizes are assumed to have a normal distribution with variance $\tau^{2}$, based on Cochran's Q statistic for heterogeneity). 
Subgroup analysis by strata of methodological quality scores ( $\geq 6$ points, 5 points, $<5$ points) was carried out to assess whether differences in the quality of the studies were a potential source of heterogeneity for each outcome. Another possible source of heterogeneity was assessed by carrying out subgroup analysis for studies which presented adjusted hazard ratios from multivariable models and for those which presented only unadjusted results.

Sensitivity analysis was carried out for studies which provided a clear definition that mortality referred to death from cancer. For the studies of colorectal carcinomas, sensitivity analysis was carried out for studies which had included an analysis of patients with stage III/IV colorectal carcinomas in their results. Small-study effects were assessed for each outcome by visual inspection of the funnel plot and an Egger's test [29].

\section{Results}

Identification and selection of included studies

The literature search retrieved a total of 3,098 studies, including 2,062 from MEDLINE, 541 from Embase, 392 from Web of Science and 103 from PubMed. A total of 48 papers were classified initially as potentially relevant and the full papers retrieved. Twenty-two potentially relevant papers were excluded for the following reasons: compared fascin-1 in normal tissues versus tumors in the same patients [30,31]; carried out studies in adenomas [5], pleomorphic carcinomas [32], or neuroendocrine tumors [33]; did not report on relevant exposure [34]; did not present outcomes on mortality, progression or metastasis [35-39]; did not present results for mortality or metastasis [22,40-43]; duplicate abstract or study [44-47], and inability to categorize fascin-1 expression [48]. We were unable to obtain one paper either electronically or after contacting the authors [49]. Overall, 26 papers published between 2003 and 2011 were included in our meta-analysis (Figure 1).

\section{Characteristics of included studies}

Only one study [24] involved a prospectively assembled cohort while the remainder studied retrospectively assembled cohorts. The median sample size of the studies was 128.5 (range 46 to 509) cases, but no studies provided a sample size or power calculation. The characteristics and key results of these studies, as published, are shown in Additional file 2.

\section{Quality of studies}

The methodological quality of the papers was assessed using the Newcastle-Ottawa scaling method [27]. For the 18 studies $[6,7,9,19-21,24,50-60]$ which examined the association of fascin- 1 with mortality, 8 studies $[6,7,9,24,52,55,56,58]$ were found to be of high methodological quality (Newcastle-Ottawa scores of above 6 points),
2 studies $[50,51]$ had a score of 5 points which is just below the threshold for high methodological quality and 8 studies [19-21,53,54,57,59,60] were of poor methodological quality (Additional file 1).

For the 6 studies $[19,21,50-53]$ which examined the association of fascin-1 with time-to-disease progression, 1 study [52] was of high methodological quality, 2 studies $[50,51]$ had quality scores just below the 'high' threshold and 3 studies $[19,21,53]$ were of poor methodological quality (Additional file 1).

For the 17 studies [6-9,11,54-58,60-66] that examined the association of fascin-1 with lymph node metastasis, 6 studies $[6,7,9,55,56,58]$ were of high methodological quality and 11 studies $[8,11,54,57,60-66]$ were of poor methodological quality (Additional file 1).

For the 9 studies $[8,9,11,52,54,55,57,58,61]$ which examined the association of fascin-1 with distant metastasis, 4 studies $[9,52,55,58]$ were of high methodological quality and 5 studies $[8,11,54,57,61]$ were of poor methodological quality (Additional file 1).

\section{Meta-analysis results}

\section{Breast carcinoma}

Three studies [19-21] examined the association of fascin-1 with mortality, with a total of 489 breast carcinoma cases. The pooled fixed effects HR estimate for fascin-1 positivity (that is, scored as positive versus negative) of the carcinomas was 2.58 (1.48 to $4.52 ; P=0.001$ ) (Figure $2 \mathrm{~A}$ ). There was moderate heterogeneity between the three cohort studies $\left(\mathrm{I}^{2}=31.4 \%\right)$, although the statistical evidence supporting heterogeneity was weak $(P=0.23)$.

Two studies $[19,21]$ examined the association of fascin-1 positivity of carcinomas with time-to-disease progression, with a total of 281 breast carcinoma cases. Based on studies examining fascin-1 positivity, the pooled fixed effects HR estimate was 2.48 (1.38 to $4.46 ; P=0.002)$ for mortality, recurrence or metastasis outcomes (Figure 3 ). There was low heterogeneity between the two cohort studies $\left(\mathrm{I}^{2}=17.4 \% ; P=0.27\right)$.

\section{Colorectal carcinoma}

Two studies [51,52] examined the association of fascin-1 positivity of carcinomas with mortality, and three $[6,24,54]$ examined the association of high fascin-1 with mortality, with a total of 1,141 colorectal carcinoma cases. The study by Ozerhan et al. [61] was excluded from the analysis as it had presented two-year mortality rates for each fascin-1 category, and we could not estimate hazard ratios. For studies examining fascin-1 positivity of the carcinomas, the pooled fixed effects HR estimate was 1.95 (1.32 to 2.87; $P=0.001$ ) (Figure 2A). Based on studies examining high fascin-1 expression, the pooled fixed effects HR estimate was 1.54 (1.3 to $1.82 ; P<0.001$ ) (Figure $2 \mathrm{~B}$ ). Pooling across all studies gave a pooled fixed effects HR estimate of 1.60 

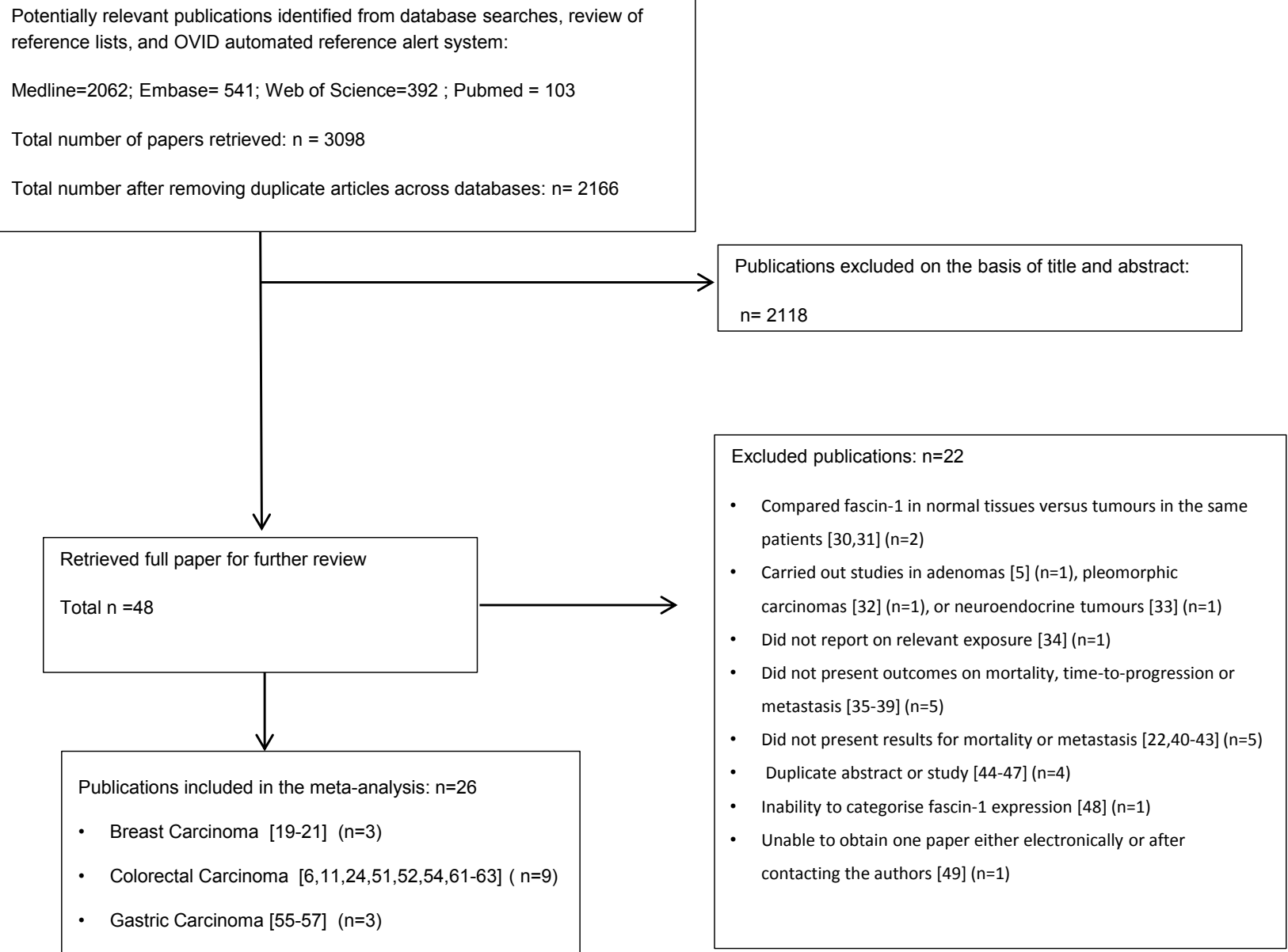

(1.37 to $1.86 ; P<0.001$ ). There was moderate heterogeneity between studies that scored fascin-1 as positive versus negative $\left(I^{2}=46.7 \% ; P=0.17\right)$. There was no heterogeneity between studies that scored fascin-1 as high vs low levels $\left(\mathrm{I}^{2}=0 \% ; P=0.64\right)$ or when all studies were pooled $\left(\mathrm{I}^{2}=0.0 \% ; P=0.41\right)$.

Two studies [51,52] examined the association of fascin-1 positivity of carcinomas with time-to-disease progression, with a total of 354 colorectal carcinoma cases. Based on studies examining fascin-1 positivity, the pooled random effects HR estimate was 2.12 (1.00 to $4.47 ; P=0.05)$ for mortality, recurrence or metastasis outcomes (Figure 3 ). There was moderate-to-high heterogeneity between the two cohort studies $\left(\mathrm{I}^{2}=73 \% ; P=0.06\right)$.

Three studies $[11,61,62]$ examined the association of fascin-1 positivity of colorectal carcinomas with lymph node metastasis and $3[6,54,63]$ examined the association of high fascin-1 with lymph node metastasis, with a total of 833 colorectal carcinoma cases. Based on studies examining fascin-1 positivity, the pooled fixed effects RR estimate was 1.64 (1.34 to $2.01 ; P<0.001$ ) (Figure $4 \mathrm{~A}$ ). Based on studies examining high fascin-1 expression, the pooled fixed effects RR estimate was 1.28 (1.01 to $1.61 ; P=0.04$ ) (Figure 4B). Pooling across all studies gave a pooled fixed effects RR estimate of 1.47 (1.26 to $1.71 ; P<0.001)$. There was no heterogeneity between studies that scored fascin-1 as positive versus negative $\left(\mathrm{I}^{2}=0 \%, P=0.4\right)$, high versus low levels $\left(\mathrm{I}^{2}=0 \%, P=0.6\right)$ or when all studies were pooled $\left(\mathrm{I}^{2}=6.4 \% ; P=0.38\right)$.

Three studies $[11,52,61]$ examined the association of fascin-1 positivity of carcinomas with distant metastasis and one [54] examined the association of high fascin-1 with 


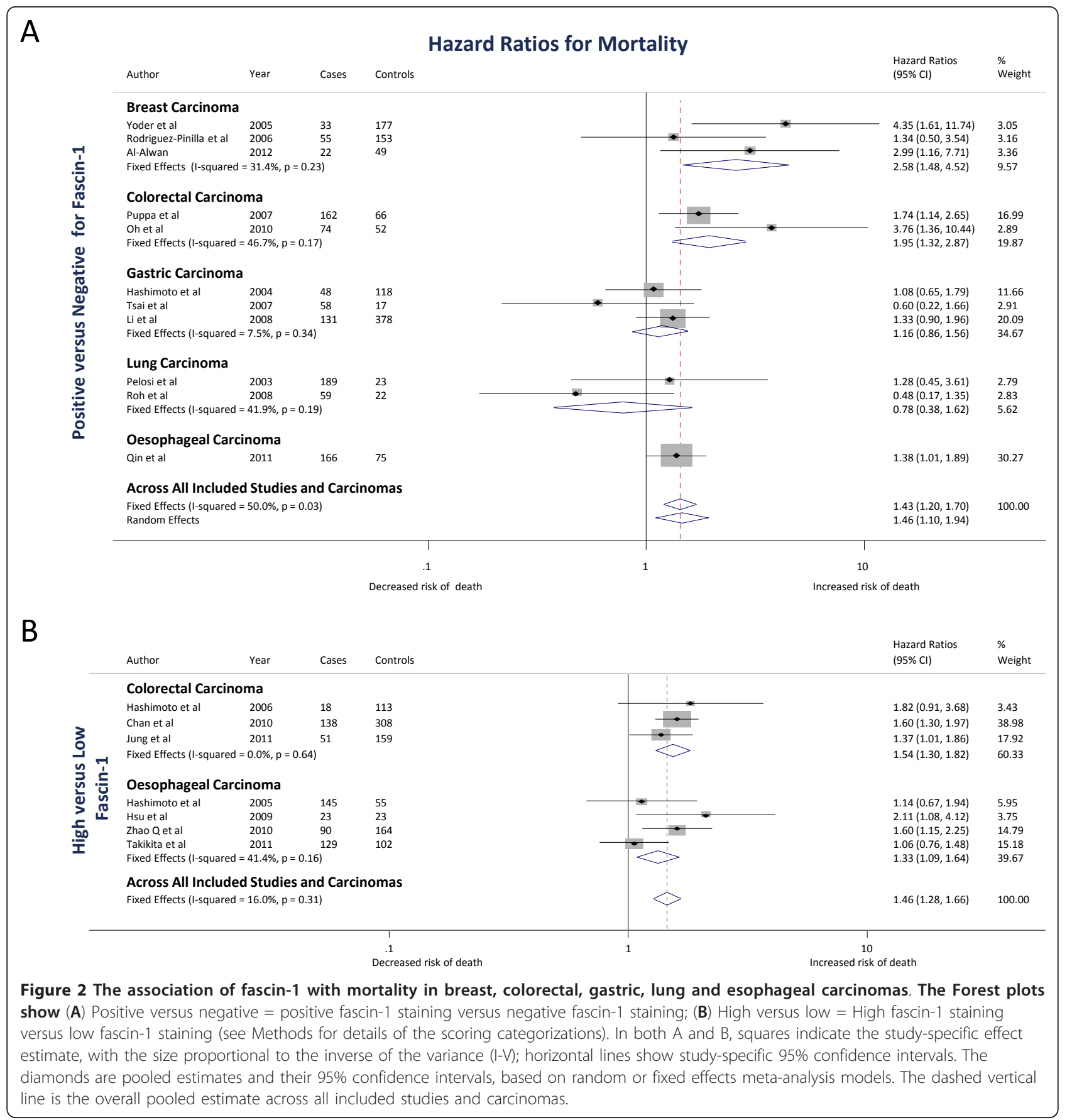

distant metastasis, with a total of 684 colorectal carcinoma cases. The study by $\mathrm{Oh}$ et al. [51] was excluded from the meta-analysis as it had presented adjusted HRs and could not be pooled with the RRs estimated in the above studies. Based on studies examining fascin-1 positivity, the pooled fixed effects RR estimate was 1.72 ( 1.17 to $2.52 ; P=0.006)$ (Figure 5A). The study examining high fascin-1 had a RR estimate of 1.56 ( 0.49 to $4.96 ; P=0.4$ ) (Figure $5 \mathrm{~B})$. Pooling across all studies gave a fixed effects RR estimate of 1.70
( 1.18 to $2.45 ; P=0.004)$. There was no heterogeneity between studies that scored fascin-1 as positive versus negative $\left(\mathrm{I}^{2}=0 \% ; P=0.65\right)$ or when all studies were pooled $\left(\mathrm{I}^{2}=0 \% ; P=0.83\right)$.

\section{Gastric carcinoma}

Three studies [55-57] examined the association of fascin-1 positivity of carcinomas with mortality, with a total of 750 gastric carcinoma cases. Based on the studies, the pooled 


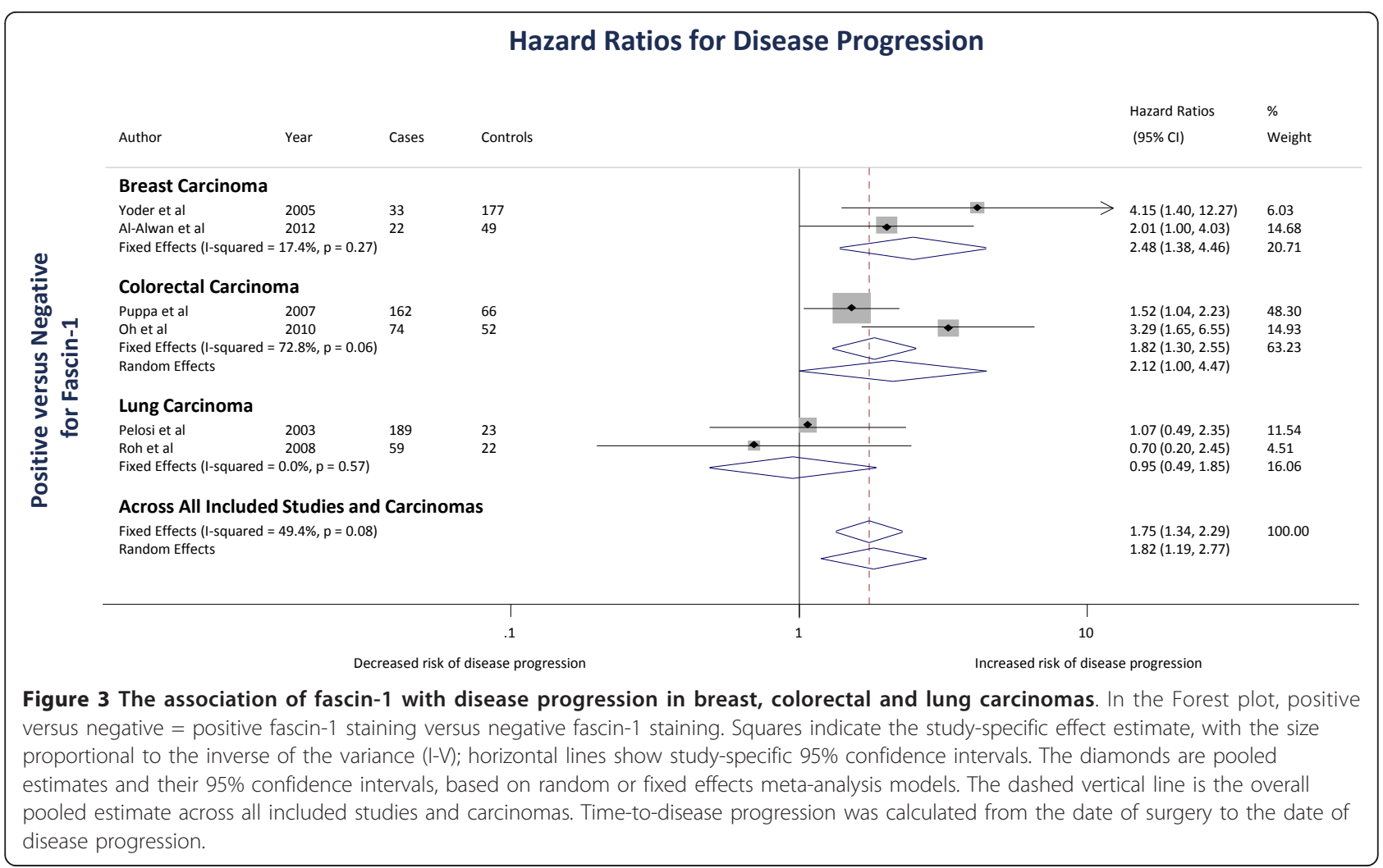

fixed effects HR estimate was 1.16 ( 0.86 to $1.56 ; P=0.33$ ) (Figure 2A). There was low heterogeneity between the three cohort studies $\left(\mathrm{I}^{2}=8 \% ; P=0.34\right)$.

Three studies [55-57] examined the association of fascin-1 positivity of carcinomas with lymph node metastasis, with a total of 823 gastric carcinoma cases. Based on the studies, the pooled fixed effects RR estimate was 1.43 (1.21 to $1.70 ; P<0.001$ ) (Figure $4 \mathrm{~A}$ ). There was no heterogeneity between the three cohort studies $\left(\mathrm{I}^{2}=0 \%\right.$; $P=0.5)$.

Two studies [55,57] examined the association of fascin-1 positivity of carcinomas with distant metastasis, with a total of 314 gastric carcinoma cases. Based on the studies, the pooled fixed effects RR estimate was 1.93 (1.12 to 3.33; $P=0.02$ ) (Figure 5A). There was no heterogeneity between the two cohort studies $\left(\mathrm{I}^{2}=0 \%\right.$; $P=0.6)$.

\section{Lung carcinoma}

Two studies [50,53] examined the association of fascin-1 positivity of carcinomas with mortality, with a total of 293 lung carcinoma cases. Based on the studies, the pooled fixed effects HR estimate was 0.78 (0.38 to 1.62; $P=0.51$ ) (Figure 2A). There was moderate heterogeneity between the two cohort studies $\left(\mathrm{I}^{2}=42 \% ; P=0.2\right)$.

Two studies [50,53] examined the association of fascin-1 positivity of carcinomas with time-to-disease progression with a total of 293 lung carcinoma cases. Based on the studies, the pooled fixed effects HR estimate was 0.95 (0.49 to $1.85 ; P=0.9$ ) for mortality, recurrence or metastasis outcomes (Figure 3). There was no heterogeneity between the two cohort studies $\left(\mathrm{I}^{2}=\right.$ $0 \% ; P=0.6)$.

Two studies [64,65] examined the association of fascin-1 positivity of carcinomas with lymph node metastasis, with a total of 147 lung carcinoma cases. Based on the studies, the pooled random effects RR estimate was 3.11 ( 0.64 to $15.25 ; P=0.2$ ) (Figure $4 \mathrm{~A}$ ). There was moderate heterogeneity between the two cohort studies $\left(\mathrm{I}^{2}=63 \% ; P=0.1\right)$.

\section{Esophageal carcinoma}

Four studies $[7,9,58,59]$ examined the association of high fascin-1 with mortality and one [60] examined the association of fascin-1 positivity of carcinomas with mortality, with a total of 972 esophageal carcinoma cases. The study examining fascin-1 positivity had a HR estimate of 1.38 (1.01 to $1.89 ; P=0.05$ ) (Figure $2 \mathrm{~A}$ ). Based on studies examining high fascin-1, the pooled fixed effects HR estimate was 1.33 (1.09 to $1.64 ; P=0.01$ ) (Figure 2B). Pooling across all studies gave a fixed effects HR estimate of 1.35 ( 1.13 to $1.60 ; P=0.001$ ). There was moderate heterogeneity between studies that scored fascin-1 as high versus low levels $\left(\mathrm{I}^{2}=41 \% ; P=0.2\right)$ and moderate 


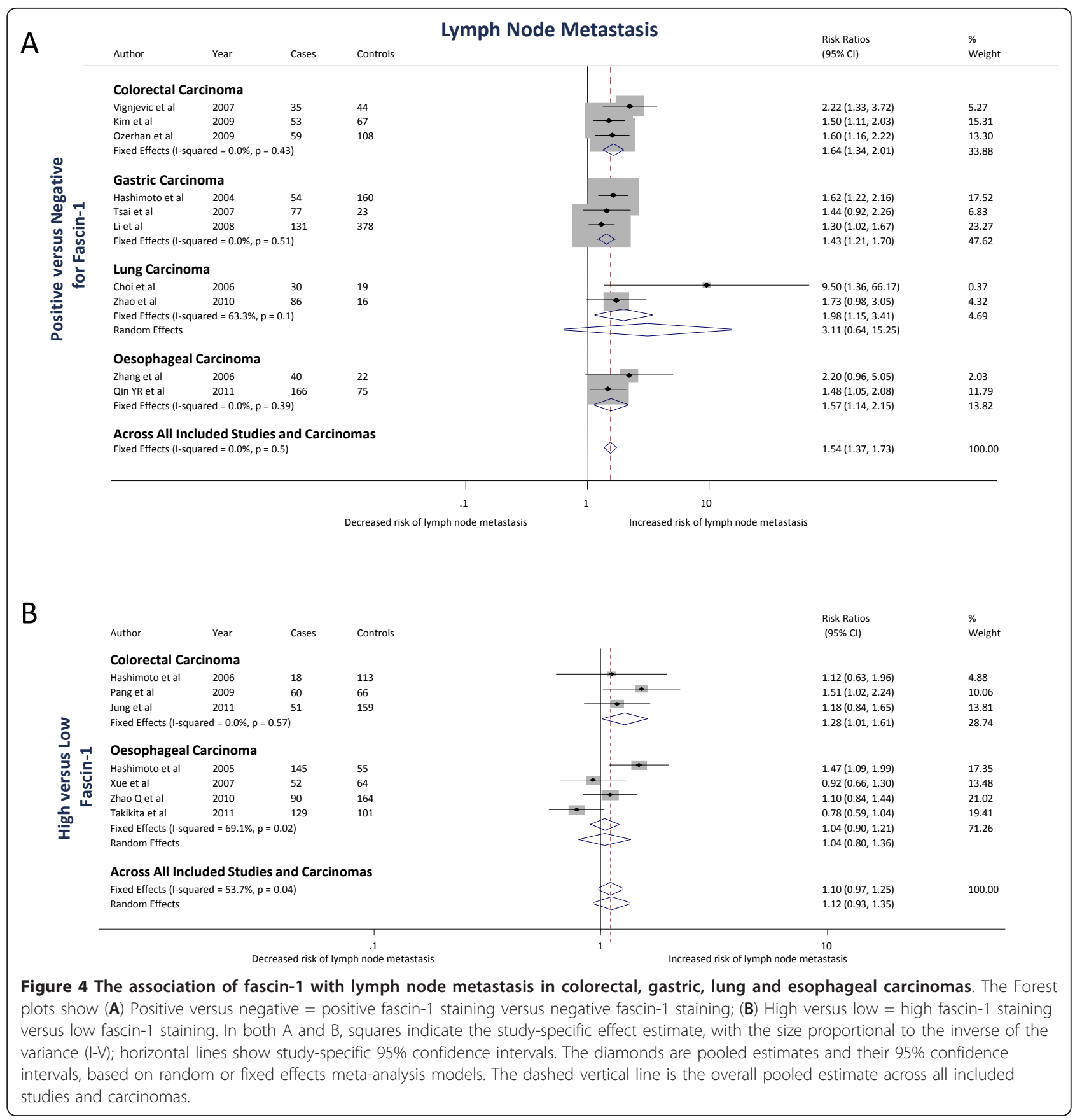

heterogeneity when all studies were pooled $\left(\mathrm{I}^{2}=22.3 \%\right.$; $P=0.27$ ).

Two studies $[8,60]$ examined the association of fascin-1 positivity of carcinomas with lymph node metastasis and four $[7,9,58,66]$ examined the association of high fascin-1 with lymph node metastasis, with a total of 1,103 esophageal carcinoma cases. Based on studies examining fascin-1 positivity, the pooled fixed effects RR estimate was 1.57 (1.14 to $2.15 ; P=0.01$ ) (Figure $4 \mathrm{~A}$ ). Based on studies examining high fascin-1, the pooled random effects $R R$ estimate was 1.04 ( 0.80 to $1.36 ; P=0.77)$ (Figure $4 \mathrm{~B})$. Pooling across all studies gave a random effects RR estimate of $1.16(0.91$ to $1.49 ; P=0.24)$. There was no heterogeneity between studies that scored fascin-1 as positive versus negative $\left(\mathrm{I}^{2}=0 \% ; P=0.4\right)$. There was moderate heterogeneity between studies that scored fascin- 1 as high versus low levels $\left(\mathrm{I}^{2}=69.1 \% ; P=0.02\right)$ or when all studies were pooled $\left(\mathrm{I}^{2}=68.1 \% ; P=0.008\right)$.

Two studies $[9,58]$ examined the association of high fascin-1 with distant metastasis and one [8] examined 


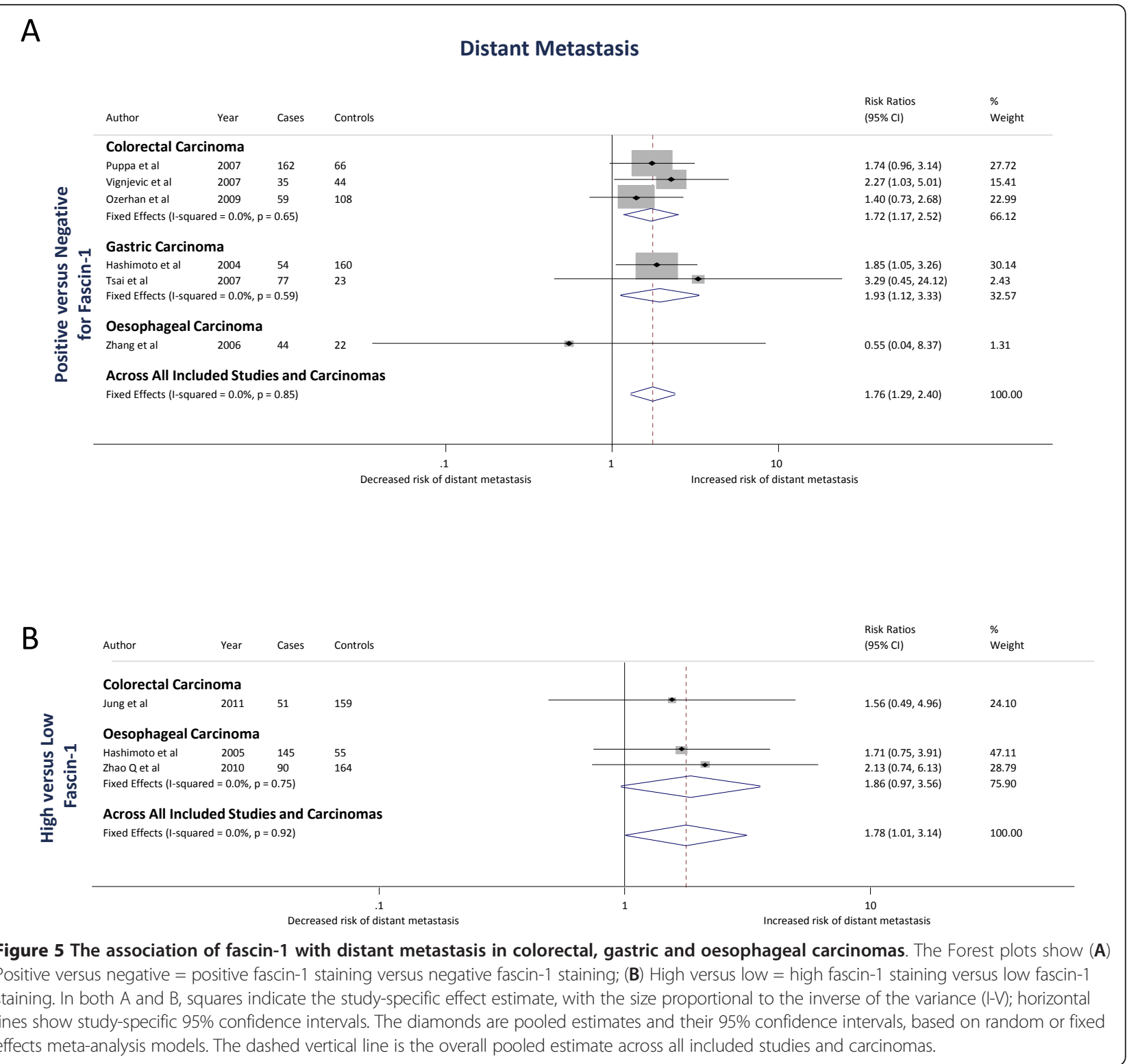

the association of fascin-1 positivity of carcinomas with distant metastasis, with a total of 516 esophageal carcinoma cases. The study examining fascin-1 positivity had a RR estimate of 0.55 (0.04 to 8.37; $P=0.7$ ) (Figure 5A). Based on studies examining high fascin-1, the pooled fixed effects RR estimate was 1.86 (0.97 to $3.56 ; P=0.06$ ) (Figure 5B). Pooling across all studies gave a pooled fixed effects RR estimate of 1.74 ( 0.92 to $3.28 ; P=0.09)$. There was no heterogeneity between studies that scored fascin-1 as high versus low levels $\left(\mathrm{I}^{2}=0 \% ; P=0.8\right)$ or when all studies were pooled $\left(\mathrm{I}^{2}=0 \% ; P=0.66\right)$.

\section{Analysis of all included carcinomas}

Eleven studies [19-21,50-53,55-57,60] examined the association of fascin-1 positivity of carcinomas with mortality and seven studies $[6,7,9,24,54,58,59]$ examined the association of high fascin-1 with mortality, with a total of 3,645 carcinoma cases. Based on studies examining fascin-1 positivity, the pooled random effects HR estimate was $1.46(1.10$ to $1.94 ; P=0.008)$ (Figure $2 \mathrm{~A})$. Based on studies examining high fascin-1, the pooled fixed effects HR estimate was $1.46(1.28$ to $1.66 ; P<0.001)$ (Figure $2 B)$. The overall pooled random effects HR estimate for the association of fascin-1 with mortality was 1.44 (1.24 to $1.68 ; P<0.001$ ). There was low heterogeneity between studies that scored fascin- 1 as high versus low levels $\left(\mathrm{I}^{2}=\right.$ $16 \% ; P=0.31$ ). There was moderate heterogeneity between studies that scored fascin-1 as positive versus negative $\left(\mathrm{I}^{2}=50 \% ; P=0.03\right)$ or when all studies were pooled $\left(\mathrm{I}^{2}=37.4 \% ; P=0.06\right)$. 
Six studies [19,21,50-53] examined the association of fascin-1 positivity with time-to-disease progression, with a total of 928 carcinoma cases. The overall random effects HR estimate for the association of fascin- 1 with time-to-disease progression was 1.82 (1.19 to $2.77 ; P=$ $0.006)$ for mortality, recurrence or metastasis outcomes (Figure 3). There was moderate heterogeneity between the studies $\left(\mathrm{I}^{2}=49.4 \% ; P=0.08\right)$.

Ten studies $[8,11,55-57,60-62,64,65]$ examined the association of fascin-1 positivity of carcinomas with lymph node metastasis and seven studies $[6,7,9,54,58,63,66]$ examined the association of high fascin-1 with lymph node metastasis, with a total of 2,906 carcinoma cases. Based on studies examining fascin-1 positivity, the pooled fixed effects RR estimate was 1.54 ( 1.37 to $1.73 ; P<0.001$ ) (Figure 4A). Based on studies examining high fascin-1, the pooled random RR estimate was 1.12 (0.93 to $1.35 ; P=$ 0.25 ) (Figure $4 B$ ). The overall pooled random effects $R R$ estimate for the association of fascin- 1 with lymph node metastasis was 1.36 ( 1.18 to $1.55 ; P<0.001)$. There was no heterogeneity between studies that scored fascin-1 as positive versus negative $\left(\mathrm{I}^{2}=0 \% ; P=0.5\right)$. There was moderate heterogeneity between studies that scored fascin- 1 as high versus low levels $\left(\mathrm{I}^{2}=53.7 \% ; P=0.04\right.$ or when all studies were pooled $\left(\mathrm{I}^{2}=55.3 \% ; P=0.003\right)$.

Six studies $[8,11,52,55,57,61]$ examined the association of fascin-1 positivity of carcinomas with distant metastasis and three studies $[9,54,58]$ examined the association of high fascin-1 with distant metastasis, with a total of 1,514 carcinoma cases. Based on studies examining fascin-1 positivity, the pooled fixed effects $R R$ estimate was 1.76 (1.29 to $2.4 ; P<0.001$ ) (Figure $5 \mathrm{~A}$ ). Based on studies examining high fascin-1, the pooled fixed RR estimate was 1.78 (1.0 to $3.14 ; P=0.05$ ) (Figure $5 \mathrm{~B}$ ). The overall pooled fixed effects RR estimate for the association of fascin-1 with distant metastasis was 1.76 (1.34 to 2.32; $P<0.001)$. There was no heterogeneity between studies that scored fascin- 1 as positive versus negative $\left(\mathrm{I}^{2}=0 \% ; P=0.85\right)$, between studies that scored fascin-1 as high versus low levels $\left(\mathrm{I}^{2}=0 \% ; P=0.92\right)$ or when all studies were pooled $\left(\mathrm{I}^{2}=0 \% ; P=0.98\right)$.

\section{Subgroup analysis}

To address if the variations in methodological quality of the studies were possible sources of heterogeneity, we carried out subgroup analysis by methodological quality scores. For the 18 studies [6,7,9,19-21,24,50-60] which examined the association of fascin- 1 with mortality, 8 studies $[6,7,9,24,52,55,56,58]$ with a high quality scores had a pooled fixed effects HR estimate of 1.43 (1.26 to 1.63; $P<0.001)$ (Table $1 \mathrm{~A}), 2$ studies [50,51] with quality scores just below the threshold had a pooled random effects $\mathrm{HR}$ estimate of $2.20(0.77$ to $6.34 ; P=0.14)$ (Table $1 \mathrm{~A})$ and 8 studies [19-21,53,54,57,59,60] with poor quality scores had a random effects HR of 1.48 (1.05 to $2.08 ; P=0.03$ ) (Table 1A).

For the 6 studies $[19,21,50-53]$ which examined the association of fascin-1 with time-to-disease progression, 1 study [52] with a high quality score had a HR of 1.52 (1.04 to $2.23 ; P<0.05), 2$ studies [50,51] with quality scores just below the threshold had a pooled random effects $\mathrm{HR}$ estimate of 1.91 ( 0.64 to $5.70 ; P=0.25$ ) (Table $1 \mathrm{~A}$ ) and 3 studies $[19,21,53]$ with poor quality scores had a pooled random effects HR estimate of 1.90 (0.81 to 4.46; $P=0.14$ ) (Table 1A).

For the 17 studies [6-9,11,54-58,60-66] which examined the association of fascin-1 with lymph node metastasis, 6 studies $[6,7,9,55,56,58]$ with high quality scores had a pooled random effects RR estimate of 1.21 ( 0.97 to 1.51 ; $P=0.09$ ) (Table $1 \mathrm{~A}$ ) and 11 studies $[8,11,54,57,60-66]$ with poor quality scores had a pooled random effects RR estimate of 1.47 (1.25 to $1.73 ; P<0.001)$ (Table $1 \mathrm{~A})$.

For the 9 studies $[8,9,11,52,54,55,57,58,61]$ which examined the association of fascin- 1 with distant metastasis, 4 studies $[9,52,55,58]$ with high quality scores had a fixed effects RR estimate of 1.81 (1.28 to 2.57 ; $P=$ 0.001 ) (Table 1A) and 5 studies $[8,11,54,57,61]$ with poor quality scores had a fixed effects RR estimate of 1.68 (1.08 to $2.62 ; P=0.02$ ) (Table $1 \mathrm{~A}$ ).

In addition, we grouped the studies according to whether they had presented adjusted or unadjusted results. Ten studies [6,7,9,24,51,52,54-56,58] presented multivariable results for the mortality outcome, with a total of 2,501 carcinoma cases. The overall pooled fixed effects HR estimate was 1.44 ( 1.28 to $1.62 ; P<0.001)$ (Table $1 \mathrm{~B})$. There was low heterogeneity between the studies $\left(\mathrm{I}^{2}=\right.$ 21.7\%; $P=0.24)$. Eight studies [19-21,50,53,57,59,60] presented unadjusted results which included results from univariable analysis and univariable Kaplan-Meier curves. The overall pooled random effects HR estimate was 1.48 (0.97 to $2.26 ; P=0.07$ ) (Table $1 \mathrm{~B}$ ). There was moderate heterogeneity between the studies $\left(\mathrm{I}^{2}=55.3 \%\right.$; $\left.P=0.03\right)$.

\section{Sensitivity analysis}

The analysis of all carcinomas indicated an association of fascin-1 with increased risk of mortality. However, not all studies had provided a clear definition of the cause of death. Therefore, we carried out a sensitivity analysis that included only studies $[6,9,19,20,51,52,54,55,58,60]$ which had provided a clear definition that "death" referred to cancer-specific mortality. The result was consistent with the analysis of all mortality outcomes (pooled fixed effects $\mathrm{HR}=1.49$ (1.29 to 1.72$) ; P<0.001)$ (Table $2 \mathrm{~A})$. A second sensitivity analysis included only studies of patients with stage III/IV colorectal carcinomas $[6,24,51,52]$. The result (pooled fixed effects $\mathrm{HR}=1.70$ (1.42 to 2.03); $P<0.001$ ) was consistent with the analyses of all stages of colorectal carcinomas (Table 2B). 


\begin{tabular}{|c|c|c|c|}
\hline Strata of analysis for each outcome & $\begin{array}{l}\text { Number of studies } \\
\text { included }\end{array}$ & $\begin{array}{l}\text { HR/RR as appropriate }(95 \% \mathrm{Cl}) \text {; } \\
P \text {-value }\end{array}$ & Heterogeneity \\
\hline \multicolumn{4}{|l|}{ A. Methological quality scores } \\
\hline \multicolumn{4}{|l|}{ Mortality } \\
\hline Studies with a score of $\geq 6$ points $[6,7,9,24,52,55,56,58]$ & 8 & 1.43 (1.26 to 1.63$) ; P<0.001$ & $I^{2}=12.4 \% ; P=0.33$ \\
\hline Studies with a score of 5 points $[50,51]$ & 2 & $2.20(0.77$ to 6.34$) ; P=0.14$ & $I^{2}=52.6 \% ; P=0.15$ \\
\hline Studies with a score of $<5$ points $[19-21,53,54,57,59,60]$ & 8 & $1.48(1.05$ to 2.08$) ; P=0.03$ & $\mathrm{I}^{2}=55.5 \% ; P=0.03$ \\
\hline \multicolumn{4}{|l|}{ Time-to-disease progression } \\
\hline Study with a score of $\geq 6$ points [52] & 1 & 1.52 (1.04 to 2.23$) ; P<0.05$ & \\
\hline Studies with a score of 5 points $[50,51]$ & 2 & $1.91(0.64$ to 5.70$) ; P=0.25$ & $P^{2}=77.4 \% ; P=0.04$ \\
\hline Studies with a score of $<5$ points $[19,21,53]$ & 3 & $1.90(0.81$ to 4.46$) ; P=0.14$ & $I^{2}=54.9 \% ; P=0.11$ \\
\hline \multicolumn{4}{|l|}{ Lymph node metatasis } \\
\hline Study with a score of $\geq 6$ points $[6,7,9,55,56,58]$ & 6 & $1.21(0.97$ to 1.51$) ; P=0.09$ & $\begin{array}{l}I^{2}=68.5 \% \\
P=0.007\end{array}$ \\
\hline Studies with a score of $<5$ points $[8,11,54,57,60-66]$ & 11 & 1.47 (1.25 to 1.73$) ; P<0.001$ & $I^{2}=38.5 \% ; P=0.09$ \\
\hline \multicolumn{4}{|l|}{ Distant metastasis } \\
\hline Studies with a score of $\geq 6$ points $[9,52,55,58]$ & 4 & $1.81(1.28$ to 2.57$) ; P=0.001$ & $I^{2}=0.0 \% ; P=0.99$ \\
\hline Studies with a score of $<5$ points $[8,11,54,57,61]$ & 5 & $1.68(1.08$ to 2.62$) ; P=0.02$ & $I^{2}=0.0 \% ; P=0.74$ \\
\hline \multicolumn{4}{|l|}{ B. Adjusted versus unadjusted results for Mortality } \\
\hline $\begin{array}{l}\text { Studies with results from multivariable analysis } \\
{[6,7,9,24,51,52,54-56,58]}\end{array}$ & 10 & 1.44 (1.28 to 1.62$) ; P<0.001$ & $P^{2}=21.7 \% ; P=0.24$ \\
\hline $\begin{array}{l}\text { Studies without results from multivariable analysis } \\
{[19-21,50,53,57,59,60]}\end{array}$ & 8 & $1.48(0.97$ to 2.26$) ; P=0.07$ & $P^{2}=55.3 \% ; P=0.03$ \\
\hline
\end{tabular}

Note: Time-to-disease progression is defined by the occurrence of the outcomes time-to-mortality, recurrence or metastasis.

Table 2 Sensitivity analyses

\begin{tabular}{|c|c|c|c|}
\hline Strata of analysis for each outcome & $\begin{array}{l}\text { Number of studies } \\
\text { included }\end{array}$ & HR (95\% Cl); P-value & Heterogeneity \\
\hline $\begin{array}{l}\text { A. Studies with definition for cancer specific mortality included } \\
{[6,9,19,20,51,52,54,55,58,60]}\end{array}$ & 10 & $1.49(1.29$ to 1.72$) ; P<0.001$ & $\begin{array}{l}P^{2}: 23.4 \% ; P= \\
0.23\end{array}$ \\
\hline \multirow[t]{3}{*}{$\begin{array}{l}\text { B. Only Stage III/IV colorectal carcinoma studies included } \\
{[6,24,51,52]}\end{array}$} & High versus Low: 2 & $\begin{array}{l}\text { High versus Low: } 1.64 \text { (1.34 to } 2.00) ; P \\
<0.001\end{array}$ & $\mathrm{I}^{2}: 0 \% ; P=0.38$ \\
\hline & $\begin{array}{l}\text { Positive versus } \\
\text { Negative: } 2\end{array}$ & $\begin{array}{l}\text { Positive versus Negative: } 1.95 \text { (1.32 to } \\
2.87) ; P=0.001\end{array}$ & $\begin{array}{l}P^{2}: 46.7 \% ; P= \\
0.17\end{array}$ \\
\hline & $\begin{array}{l}\text { Overall colorectal } \\
\text { studies: } 4\end{array}$ & $\begin{array}{l}\text { Overall colorectal studies: } 1.70(1.42 \text { to } \\
2.03) ; P<0.001\end{array}$ & $\begin{array}{l}P^{2}: 7.2 \% ; P= \\
0.36\end{array}$ \\
\hline
\end{tabular}

\section{Publication bias}

We investigated for the potential presence of publication bias through visual inspection of funnel plot asymmetry and by computation of Egger's test. For the mortality, time-to-disease progression and distant metastasis outcomes, data points in the funnel plot analyses approximated a symmetrical distribution indicating that publication bias is unlikely to be present in our analyses (Figure 6). For the lymph node metastasis outcome Egger's $P$-value for funnel plot asymmetry was 0.05 . Visual inspection of the funnel plot for lymph node metastasis, (Figure 6), showed that two studies, $[8,64]$, were highly influential in the result of Egger's asymmetry test. After exclusion of these two studies, the data points in the funnel plot analysis approximated a symmetrical distribution with no evidence of bias (Egger's test: $P=0.27$ ) (Additional file 3).

\section{Discussion}

The importance of demonstrating the reproducibility of biomarker studies to validate their utility for the clinic is increasingly well recognized [67]. Our systematic review and meta-analysis is the first investigation of the overall worldwide evidence on the association of the actin-bundling protein fascin-1 with mortality, time-to-disease progression, lymph node metastasis and distant metastasis, in some of the most prevalent forms of carcinoma.

Our meta-analyses demonstrate that there is strong evidence that fascin-1 protein is associated with an up to two and a half-fold increased risk of mortality in breast, colorectal and esophageal carcinomas. At present, there is little evidence that fascin-1 is associated with mortality for gastric and lung carcinomas. Fascin-1 is correlated with increased risk of disease progression in breast and colorectal carcinomas, but not in lung carcinoma. Strong 


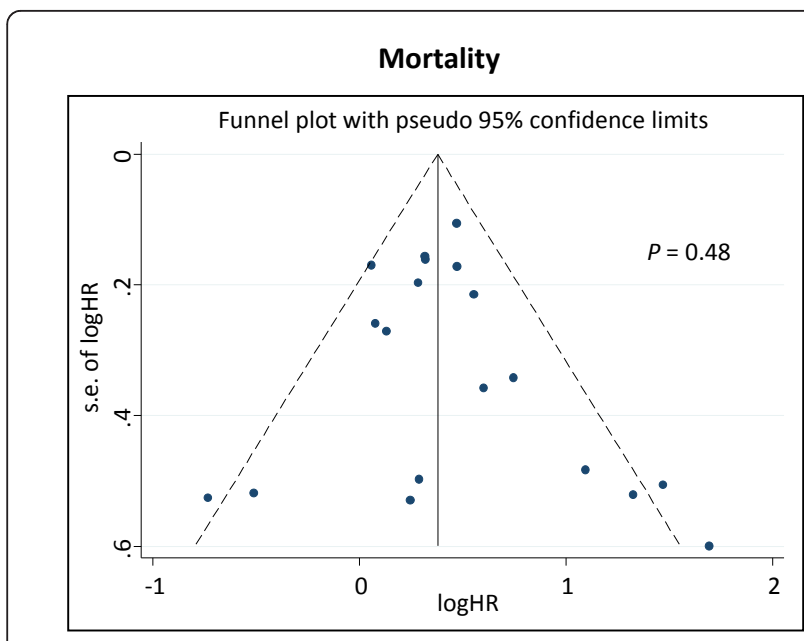

\section{Lymph node Metastasis}

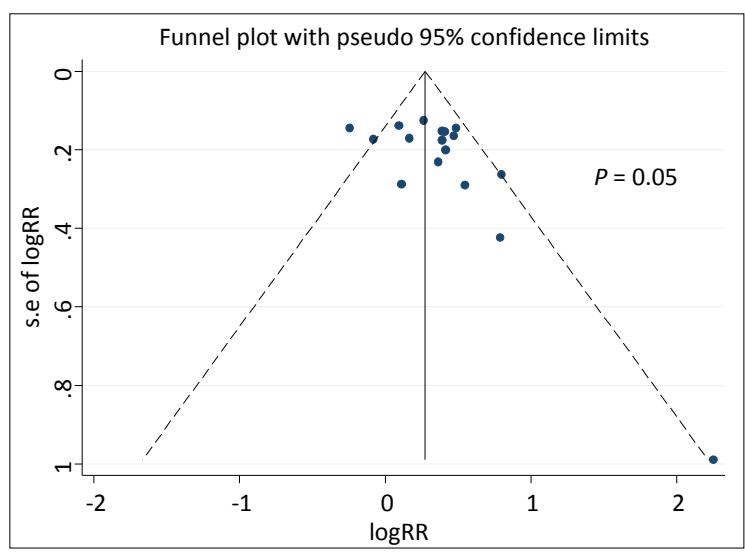

Disease progression

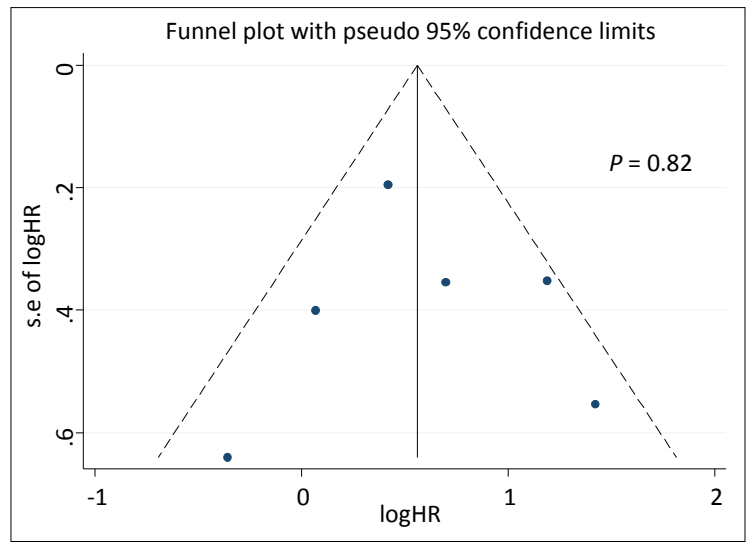

Distant Metastasis

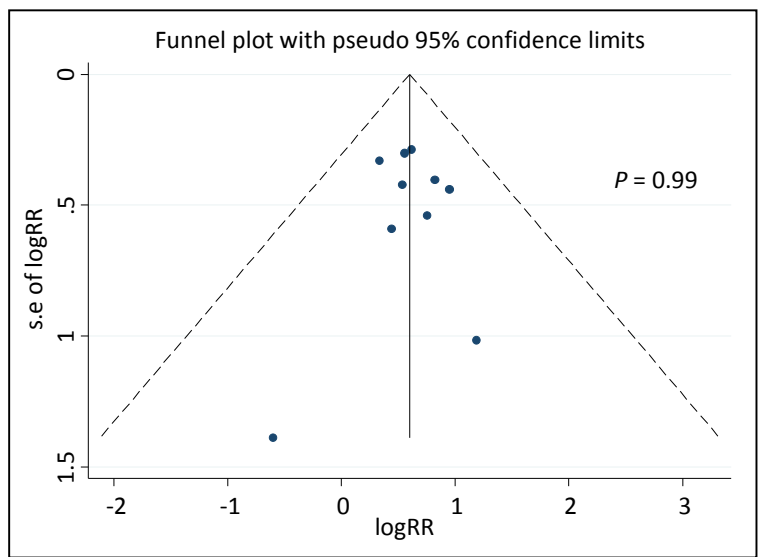

Figure 6 Assessment of publication bias for mortality, disease progression analysis, lymph node metastasis and distant metastasis. In each funnel plot analysis, black dots represent each study's effect estimate (drawn on a log scale) plotted against its standard error. The outer dashed lines represent the $95 \%$ confidence limits around the summary effect estimate, within which 95\% of studies are expected to lie in the absence of either biases or heterogeneity. P-values are from the results of Egger's test to assess publication bias.

evidence for association of fascin-1 with increased risk of lymph node metastasis was found for colorectal and gastric carcinomas, but not for lung and esophageal carcinomas. Fascin-1 protein was also associated with a greater than $70 \%$ increased risk of distant metastasis in colorectal, gastric and esophageal carcinomas, although the statistical evidence for association with esophageal carcinoma metastasis was weak.

The potential for search and inclusion bias in our metaanalysis is considerably reduced as we conducted a comprehensive search of four databases for papers published in all languages. Publication bias could result from selective reporting of results by individual studies, because statistically insignificant results are often not published $[68,69]$. Many authors did not respond to requests for information or clarification and we also identified several studies which did not report all their data. However, funnel plot analyses were not generally indicative of any strong publication bias because visual inspection of funnel plots did not show asymmetry (Figure 6). There was potential for misclassification of outcome, because some studies did not provide a clear definition of the cause of death. However, sensitivity analysis of studies that had provided a clear definition of cancer-specific mortality demonstrated that fascin-1 expression was associated with a $49 \%$ increased risk of cancer-specific death. This effectestimate was similar to the pooled results from studies that did not have a clear definition of the cause of death (Table 2A).

All esophageal carcinoma studies included in our metaanalysis were carried out in Asia. Esophageal carcinoma shows marked geographic variation with exceptionally high rates in Asia [70]. However, rates of esophageal adenocarcinomas are increasing rapidly in several Western 
countries [71]. To exclude ethnicity and locality as modifying factors, more studies should be carried out to assess the association between fascin-1 and risk of esophageal cancer-specific mortality in Western countries.

All the included studies used immunohistochemical analysis of archived tumor specimens to quantify fascin1. Immunohistochemistry is a pathologist-based scoring system that is the most commonly used and reliable technique in diagnostic histopathology [72]. In addition, nearly all included studies used the same two antibodies to fascin-1, enabling comparability of prognostic effects in our meta-analysis. Only one cohort [24] was prospectively assembled. The remaining studies were retrospective in design using samples based on the availability of specimens with interpretable cores (which may have been non-random) and clinical histories, rather than specifying and recruiting a truly representative sample from a clearly defined target population. No studies provided an appropriate justification of the sample size or a power calculation. In addition, there was limited control for confounding in the analysis of most datasets and incomplete ascertainment of outcome data, due to loss to follow-up, which can lead to biased effect-estimates. Therefore, most of the studies included in our metaanalysis were assessed as having a risk of bias. For the 18 studies examining associations of fascin- 1 with mortality, only 8 studies, $[6,7,9,24,52,55,56,58]$, were found to be of high methodological quality. We were somewhat reassured, however, that the high quality studies showed a positive association between fascin-1 expression and mortality (pooled fixed effects HR: 1.43 (1.26 to $1.63 ; P<0.001$ ), that was similar in magnitude to the association observed when all 18 studies were pooled (pooled random effects HR: 1.44 (1.24 to $1.68 ; P<0.001$ ).

The scoring of fascin-1 by immunohistochemistry is a continuous measurement and in most publications researchers categorized tumor specimens into high/positive fascin-1 or low/negative fascin-1 based on different semi-quantitatively assessed cut-off points. For example, two studies $[58,66]$ categorized 0 to 8 as low expression and 9 to 12 as high expression.

On the other hand, another study [9] dichotomized low expression as a score of $<75 \%$ immunoreactive tumor cells and high expression as $>75 \%$ immunoreactive tumor cells. These differences could possibly discard potentially important quantitative information and reduce statistical power to detect real associations [73]. There was also qualitative evidence of heterogeneity between the individual studies, but based on the number of available studies for each carcinoma type, it was not possible to investigate this statistically using metaregression (apart from stratifying by scoring method). However, a recent meta-analysis of other immunohistochemical prognostic markers demonstrated that the cut- off value of the percentage of positively-stained cells used in the scoring criteria appears unlikely to bias the underlying relationship between a prognostic biomarker and mortality [74]. With regard to future studies of fascin-1, our analyses indicate that scoring of tumors as fascin- 1 negative (taken either as completely absent $[52,61]$, below $5 \%$ fascin-1 positive cells within a tumor $[21,50,53,55-57$, $60,64]$, or below $10 \%$ fascin-1 positive cells within a tumor $[19,20,51,62]$ ) versus fascin-1 positive (that is, either more than $5 \%$ or $10 \%$ fascin-1 positive cells within a tumor) is adequate to detect an association of fascin-1 with risk of mortality (Figure 2). The validity of this simple scoring metric should facilitate clinical application of fascin-1 as a biomarker.

Metastasis is the major source of cancer-related mortality and, at the cellular level, a major effect of fascin- 1 is in promoting carcinoma cell migration and invasion. Promotion of metastasis by fascin-1 has been reported in several mouse tumor xenograft models [10-13]. Pooling across all the included carcinomas in our dataset, we obtained strong evidence that fascin-1 is associated with increased risk of mortality, lymph node metastasis and distant metastasis. However, there was evidence of heterogeneity between different carcinomas. This could be expected due to the biological differences in mechanisms of carcinoma progression for different organs. For example, the weak association between fascin- 1 and metastasis in esophageal carcinomas could be due to the rapid progression to metastatic disease that occurs in most patients with esophageal carcinoma. This is due to the unique anatomy of the esophagus which lacks serosa, thus making it easier for early rapid tumor cell spread through the extensive network of lymph nodes [75,76]. This disease course is very different from that of breast or colon carcinomas that develop through distinct stages to an aggressive phenotype over many years.

Heterogeneity was also apparent within carcinoma types. The three breast carcinoma studies showed evidence of heterogeneity for mortality $\left(\mathrm{I}^{2}=31.4 \%\right)$. However, it should be noted that each study included different histological types of breast carcinomas. Yoder et al. [19] studied primary node-positive and node-negative invasive breast carcinomas, which included infiltrating ductal carcinomas, infiltrating lobular carcinomas, mucinous carcinomas and medullary carcinomas. Al-Alwan et al. [21] studied invasive ductal carcinoma only, and Rodriguez-Pinilla et al. [20] investigated node-negative sporadic and hereditary invasive breast carcinomas. As breast cancer is a clinically heterogeneous disease [77], the heterogeneity identified in the meta-analysis could be due to the pooling of results across different subtypes of breast carcinomas. Further analyses of the association of fascin-1 with breast cancer mortality or metastasis will need to specifically evaluate different sub-types of breast carcinomas. 
In contrast, all the esophageal carcinoma studies had analyzed squamous cell carcinomas (Additional file 2); thus the between study heterogeneity is not due to pooling of results across biologically different tumors within the same organ.

Heterogeneity was also evident between the lung carcinoma studies $\left(\mathrm{I}^{2}=41.9 \%\right)$. All the studies in our dataset had analyzed only non-small cell lung carcinomas, which include both squamous cell carcinomas and adenocarcinomas. Patients with pulmonary squamous cell carcinoma have a higher mortality rate than those with adenocarcinomas, which might be attributable to confounding factors, such as smoking status and age-related co-morbidities $[78,79]$. Adenocarcinomas include different subtypes such as acinar, papillary, bronchioalveolar carcinoma and adenocarcinomas with mixed subtypes, which could account for the histological heterogeneity. One study reported that fascin-1 immuno-staining was more common in adenocarcinomas with prevalent invasive components of the acinar, papillary and solid types compared to adenocarcinomas with a prevalent bronchiolo-alveolar component [50]. Thus, the observed heterogeneity in these studies could be due to differences in fascin-1 immunostaining among different subtypes of adenocarcinomas.

Differences in patient selection and disease etiology could also explain the heterogeneity between studies of colorectal carcinomas. Most analyses included all stages of colorectal carcinomas in their specimen sets $[6,11,48,54,61-63]$, nevertheless, multiple studies reported important correlations of fascin-1 expression with increased mortality for stage III and IV tumors $[6,24,51,52]$, as confirmed by our sensitivity analysis results (Table $2 \mathrm{~B}$ ). Historically, the majority of colon adenocarcinomas originate in the left (distal) colon, yet the prevalence of right-sided (proximal) tumors is increasing [80] and multiple studies correlated high fascin1 expression with right-sided (proximal) colonic tumors $[6,24,61,62]$. In addition, rectal carcinomas have different biological, clinicopathologic and therapeutic implications from colon carcinomas $[52,81]$. It would be preferable for future studies to analyze the association of fascin- 1 with colorectal carcinomas specifically within stages and according to tumor location $[24,52]$.

For our meta-analysis of the association of fascin- 1 with mortality, we extracted multivariable analysis results from most studies, except one, [59], which presented univariable analysis results and seven studies, [19-21,50,53,57,60], which presented results as univariable Kaplan-Meier curves. Subgroup analysis of studies that presented multivariable analysis results showed that fascin-1 protein was associated with a $44 \%$ increased risk of mortality. Ideally, meta-analysis would be based on the data of individual patients to allow for standardized control for confounding across all studies [82]. As the hazard ratios from different studies have been adjusted for different confounders, we were unable to assess the independent role of fascin- 1 as a new marker over existing markers [68].

\section{Conclusions}

Our meta-analysis study demonstrates that fascin- 1 is associated with increased risk of mortality in breast, colorectal and esophageal carcinomas and with increased risk of metastasis in colorectal and gastric carcinomas. The results were stable to a variety of sensitivity analyses and did not vary by predefined subgroups. Due to limitations of the individual studies to date (issues of methodological quality due to retrospective study designs, inadequate sample size or power justification, possible biases due to selective reporting and heterogeneity in study methodologies), adequately powered prospective studies, particularly in breast, colorectal, gastric and esophageal carcinomas, will be needed to fully determine the relative independent prognostic impact of fascin-1. Pooled analysis of all carcinomas within our dataset provides strong evidence that fascin-1 may have potential as a novel biomarker for early identification of aggressive and metastatic tumors. These data will assist rational decision making for focusing ongoing efforts investigating fascin- 1 as a biomarker onto the most relevant carcinomas.

\section{Additional material}

Additional file 1: Supplementary data on the data extraction and analysis methods. 1. Search terms used. 2. Newcastle-Ottawa Scale results for studies analysing mortality. 3. Alternative scoring methodologies used to assess immunohistochemical staining of Fascin-1. 4. Method used to derive hazard ratios from the Kaplan-Meier curve analysis.

Additional file 2: Study characteristics and key results of papers included in our meta-analysis. Data were extracted from the indicated publications as described in the Methods. Blank category boxes indicate that this data category was absent from the publication.

Additional file 3: Funnel plot analysis for lymph node metastasis after excluding studies [8,64]. Black dots represent each study's effect estimate (drawn on a log scale) plotted against its standard error. The outer dashed lines represent the 95\% confidence limits around the summary effect estimate, within which $95 \%$ of studies are expected to lie in the absence of both biases and heterogeneity. $P$-values are for the results of Egger's test to assess publication bias.

\section{Abbreviations}

Cl: Confidence Interval; HR: Hazard Ratio; I-V: Inverse of the variance; kDa: kiloDalton; MeSH: Medical Subject Headings; mRNA: messenger RNA; PRISMA: Preferred Reporting Items for Systematic Reviews and MetaAnalyses; RR: Risk Ratio; $\tau^{2}$ : tau-squared.

\section{Authors' contributions}

RMM and JCA had the idea for and designed the study. WY searched for and collected the data. RMM and WYT carried out independent review of eligible articles. VYT extracted the data, which was checked by RMM and SJL. RMM and VYT carried out analysis and interpretation of data, with input from JCA. RMM, SJL and VYT carried out secondary data analysis to test the robustness of the data. WYT prepared the first draft. All authors were involved in writing the manuscript and approved the final version. 


\section{Competing interests}

The authors declare that they have no conflicts of interest.

\section{Acknowledgements}

We thank all the authors who provided additional information about their studies. VYT is the recipient of a four-year PhD studentship from the Wellcome Trust (WT083431). The funding source had no involvement in this study.

\section{Author details}

'School of Social and Community Medicine, University of Bristol, 39 Whatley Road, Bristol BS8 2PS, UK. ${ }^{2}$ School of Biochemistry, University of Bristol, Medical Sciences Building, University Walk, Bristol BS8 1TD, UK.

Received: 11 May 2012 Accepted: 26 February 2013

Published: 26 February 2013

\section{References}

1. Diamandis EP: Cancer biomarkers: can we turn recent failures into success? J Natl Cancer Inst 2010, 102:1462-1467.

2. Hashimoto Y, Kim DJ, Adams JC: The roles of fascins in health and disease. J Pathol 2011, 224:289-300

3. Hashimoto Y, Skacel M, Adams JC: Roles of fascin in human carcinoma motility and signaling: prospects for a novel biomarker? Int J Biochem Cell Biol 2005, 37:1787-1804.

4. Machesky LM, Li A: Fascin: invasive filopodia promoting metastasis. Commun Integr Biol 2010, 3:263-270

5. Qualtrough D, Singh K, Banu N, Paraskeva C, Pignatelli M: The actin-bundling protein fascin is overexpressed in colorectal adenomas and promotes motility in adenoma cells in vitro. Br J Cancer 2009, 101:1124-1129.

6. Hashimoto Y, Skacel M, Lavery IC, Mukherjee AL, Casey G, Adams JC: Prognostic significance of fascin expression in advanced colorectal cancer: an mmunohistochemical study of colorectal adenomas and adenocarcinomas. BMC Cancer 2006, 6:241.

7. Takikita M, Hu N, Shou JZ, Giffen C, Wang QH, Wang C, Hewitt SM, Taylor PR: Fascin and CK4 as biomarkers for esophageal squamous cell carcinoma. Anticancer Resh 2011, 31:945-952.

8. Zhang H, Xu L, Xiao D, Xie J, Zeng H, Cai W, Niu Y, Yang Z, Shen Z, Li E: Fascin is a potential biomarker for early-stage oesophageal squamous cell carcinoma. J Clin Pathol 2006, 59:958-964.

9. Hashimoto $\mathrm{Y}$, Ito $\mathrm{T}$, Inoue $\mathrm{H}$, Okumura $\mathrm{T}$, Tanaka E, Tsunoda $\mathrm{S}$, Higashiyama M, Watanabe G, Imamura M, Shimada Y: Prognostic significance of fascin overexpression in human esophageal squamous cell carcinoma. Clin Cancer Res 2005, 11:2597-2605.

10. Hashimoto Y, Parsons M, Adams JC: Dual actin-bundling and protein kinase C- binding activities of fascin regulate carcinoma cell migration downstream of Rac and contribute to metastasis. Mol Biol Cell 2007, 18:4591-4602.

11. Vignjevic D, Schoumacher M, Gavert N, Janssen KP, Jih G, Lae M, Louvard D, Ben-Ze'ev A, Robine S: Fascin, a novel target of beta-Catenin-TCF signaling, is expressed at the invasive front of human colon cancer. Cancer Res 2007, 67:6844-6853.

12. Darnel AD, Behmoaram E, Vollmer RT, Corcos J, Biijan K, Sircar K, Su J, Jiao JS, Alaoui-Jamali MA, Bismar TA: Fascin regulates prostate cancer cell invasion and is associated with metastasis and biochemical failure in prostate cancer. Clin Cancer Res 2009, 15:1376-1383.

13. Chen L, Yang S, Jakoncic J, Zhang JJ, Huang XY: Migrastatin analogues target fascin to block tumour metastasis. Nature 2010, 464:1062-1066.

14. Lecomte N, Njardarson JT, Nagorny P, Yang G, Downey R, Ouerfelli O, Moore MA, Danishefsky SJ: Emergence of potent inhibitors of metastasis in lung cancer via syntheses based on migrastatin. Proc Natl Acad SCi USA 2011, 108:15074-15078.

15. Kim SJ, Choi IJ, Cheong TC, Lee SJ, Lotan R, Park SH, Chun KH: Galectin-3 increases gastric cancer cell motility by up-regulating fascin-1 expression. Gastroenterology 2010, 138:1035-1045.

16. Minn AJ, Gupta GP, Siegel PM, Bos PD, Shu W, Giri DD, Viale A, Olshen AB, Gerald WL, Massague J: Genes that mediate breast cancer metastasis to lung. Nature 2005, 436:518-524.

17. Zhang $Y$, Tong $X$ : Expression of the actin-binding proteins indicates that cofilin and fascin are related to breast tumour size. J Int Med Res 2010, 38:1042-1048.
18. Pinkus GS, Pinkus JL, Langhoff E, Matsumura F, Yamashiro S, Mosialos G, Said JW: Fascin, a sensitive new marker for Reed-Sternberg cells of Hodgkin's disease. Evidence for a dendritic or B cell derivation? Am J Pathol 1997, 150:543-562.

19. Yoder BJ, Tso E, Skacel M, Pettay J, Tarr S, Budd T, Tubbs RR, Adams JC, Hicks DG: The expression of fascin, an actin-bundling motility protein, correlates with hormone receptor-negative breast cancer and a more aggressive clinical course. Clin Cancer Res 2005, 11:186-192.

20. Rodriguez-Pinilla SM, Sarrio D, Honrado E, Hardisson D, Calero F, Benitez J, Palacios J: Prognostic significance of basal-like phenotype and fascin expression in node-negative invasive breast carcinomas. Clin Cancer Res 2006, 12:1533-1539.

21. Al-Alwan M, Olabi S, Ghebeh H, Barhoush E, Tulbah A, Al-Tweigeri T, Ajarim D, Adra C: Fascin is a key regulator of breast cancer invasion that acts via the modification of metastasis-associated molecules. PLOS ONE 2011, 6:e27339.

22. Grothey A, Hashizume R, Sahin AA, McCrea PD: Fascin, an actin-bundling protein associated with cell motility, is upregulated in hormone receptor negative breast cancer. Br J Cancer 2000, 83:870-873.

23. Parkin DM, Bray F, Ferlay J, Pisani P: Global cancer statistics, 2002. CA Cancer J Clin 2005, 55:74-108

24. Chan C, Jankova L, Fung CL, Clarke C, Robertson G, Chapuis PH, Bokey L, Lin $B P$, Dent $O F$, Clarke $S$ : Fascin expression predicts survival after potentially curative resection of node-positive colon cancer. Am J Surg Pathol 2010, 34:656-666.

25. Tierney JF, Stewart LA, Ghersi D, Burdett S, Sydes MR: Practical methods for incorporating summary time-to-event data into meta-analysis. Trials 2007, 8:16.

26. Duchateau L, Collette L, Sylvester R, Pignon JP: Estimating number of events from the Kaplan-Meier curve for incorporation in a literaturebased meta-analysis: what you don't see you can't get! Biometrics 2000, 56:886-892.

27. Wells GA, Shea B, O'Connell D, Peterson J, Welch V, Losos M, Tugwell P: The Newcastle-Ottawa Scale (NOS) for assessing the quality of nonrandomized studies in meta-analysis. [http://www.ohri.ca/programs/ clinical epidemiology/oxford.htm]

28. Higgins JP, Thompson SG, Deeks JJ, Altman DG: Measuring inconsistency in meta-analyses. BMJ 2003, 327:557-560.

29. Egger M, Davey Smith G, Schneider M, Minder C: Bias in meta-analysis detected by a simple, graphical test. BMJ 1997, 315:629-634

30. Gao X, Wu DH: Fascin expression in human epithelial tumors and its clinical significance. Nan Fang Yi Ke Da Xue Xue 2008, 28:953-955.

31. Xue LY, Zou SM, Zheng S, Xie YQ, Wen P, Liu XY, Lin DM, Lu N: Expression of fascin and CK14 in different histological types of cancer and its differential diagnostic significance. Zhonghua Zhong Liu Za Zhi 2010, 32:838-844.

32. Pelosi G, Fraggetta F, Nappi O, Pastorino U, Maisonneuve P, Pasini F, lannucci A, Solli P. Musavinasab HS, De Manzoni G, Terzi A, Viale G: Pleomorphic carcinomas of the lung show a selective distribution of gene products involved in cell differentiation, cell cycle control, tumor growth, and tumor cell motility - a clinicopothologic and immunohistochemical study of 31 cases. Am J Surg Pathol 2003, 27:1203-1215.

33. Pelosi G, Pasini F, Fraggetta F, Pastorino U, lannucci A, Maisonneuve $P$, Arrigoni G, De Manzoni G, Bresaola E, Viale G: Independent value of fascin immunoreactivity for predicting lymph node metastases in typical and atypical pulmonary carcinoids. Lung Cancer 2003, 42:203-213.

34. Hashimoto Y, Skacel M, Adams JC: Association of loss of epithelial syndecan-1 with stage and local metastasis of colorectal adenocarcinomas: an immunohistochemical study of clinically annotated tumors. BMC Cancer 2008, 8:185.

35. Chikman B, Lavy R, Tolstov G, Habler L, Kapiev A, Halevy A, Sandbank J: Significance of Fascin expression in high grade breast cancer. Ann Surg Oncol 2010, 17:S57-S57.

36. Erdogan G, Pestereli HE, Colak T, Karaveli FS, Akaydin M: Fascin expression in invasive ductal carcinoma of breast. Turk Patoloji Dergisi/Turk J Pathol 2010, 26:130-135.

37. Kanber $\mathrm{Y}, \mathrm{Xu} \mathrm{YH}$, Hartmann DP, Azumi N: Fascin is overexpressed in poorly differentiated colonic carcinomas: possible prognostic indicator of colonic cancer. Am J Clin Pathol 2004, 122:642-642.

38. Kefeli M, Sengul AT, Yildiz L, Baris S, Basoglu A, Kandemir B: EMMPRIN and fascin expression in non-small cell lung carcinoma. Cent Eur J Med 2010, 5:659-665 
39. Sarrio D, Rodriguez-Pinilla SM, Hardisson D, Cano A, Moreno-Bueno G, Palacios J: Epithelial-mesenchymal transition in breast cancer relates to the basal-like phenotype. Cancer Res 2008, 68:989-997.

40. del Rosario A, Goncharuk VN, Tran TA, Sheehan CE, Ross JS: Fascin immunoreactivity correlates with tumor grade in non-small cell lung cancer (NSCLC). Lab Invest 2001, 81:218A.

41. Goncharuk V, Arun B, Middleton L, Sahin A: Assessment of actin-binding protein fascia expression in stage I and II invasive breast cancer. A significant correlation with aggressive clinical behavior. Lab Invest 2003, 83:30A

42. Lee JH, Bae BH, Lee JM, Kim JM, Hwang JY, Goo JM, Jang JS, Roh MW, Choi SR, The prognostic significance of fascin expression in colorectal carcinoma, Integrating Science and Technology in Clinical Gastroenterology: Asian Pacific Digestive Week 2011 (APDW) Singapore, 1-4 October 2011. J Gastroenterol Hepatol 2011, 26:225.

43. Zheng HC, Zheng YS, Xia P, Xu XY, Xing YN, Takahashi H, Guan YF, Takano $Y$ : The pathobiological behaviors and prognosis associated with Japanese gastric adenocarcinomas of pure WHO histological subtypes. Histol Histopathol 2010, 25:445-452.

44. Grothey A, Hashizume R, Sahin AA, McCrea PD: Fascin, an actin-bundling protein associated with cell motility, is upregulated in hormone receptor negative breast cancer. Eur J Cancer 1999, 35:S200.

45. Rodriguez-Pinilla SM: Fascin and caveolin expression are associated with the basal-like subtype of invasive breast carcinoma. Virchows Archiv 2005, 447:244-245.

46. Xie JJ: Involvement of CYR61 and CTGF in the fascin-mediated proliferation and invasiveness of esophageal squamous cell carcinomas cells. Am J Pathol 2010, 176:939-951.

47. Xue L, Hu N, Song Y, Zou S, Shou J, Qian L, Ren L, Lin D, Tong T, He Z, Zhan QM, Taylor PR, Lu N: Tissue microarray analysis reveals a tight correlation between protein expression pattern and progression of esophageal squamous cell carcinoma. BMC Cancer 2006, 6:296.

48. Tsai WC, Chao YC, Sheu LF, Chang JL, Nieh S, Jin JS: Overexpression of fascin-1 in advanced colorectal adenocarcinoma: tissue microarray analysis of immunostaining scores with clinicopathological parameters. Dis Markers 2007, 23:153-160.

49. Nese N, Kandiloglu AR, Simsek G, Lekili M, Ozdamar A, Catalkaya A, Coskun $\mathrm{T}$ : Comparison of the desmoplastic reaction and invading ability in invasive ductal carcinoma of the breast and prostatic adenocarcinoma based on the expression of heat shock protein 47 and fascin. Anal Quant Cytol Histol 2010, 32:90-101.

50. Pelosi G, Pastorino U, Pasini F, Maissoneuve P, Fraggetta F, lannucci A, Sonzogni A, De Manzoni G, Terzi A, Durante E, Bresaola E, Pezzella F, Viale G: Independent prognostic value of fascin immunoreactivity in stage I nonsmall cell lung cancer. Br J Cancer 2003, 88:537-547.

51. Oh SY, Kim YB, Suh KW, Paek OJ, Moon HY: Prognostic impact of fascin-1 expression is more significant in advanced colorectal cancer. J Surg Res 2012, 172:102-108

52. Puppa G, Maisonneuve P, Sonzogni A, Masullo M, Chiappa A, Valerio M, Zampino MG, Franceschetti I, Capelli P, Chilosi M, Menestrina F, Viale G, Pelosi G: Independent prognostic value of fascin immunoreactivity in stage III-IV colonic adenocarcinoma. Br J Cancer 2007, 96:1118-1126.

53. Roh MS, Um SJ, Choi Y, Kim KN, Pil JC, Lee SK, Son C, Yang D: Prognostic significance of fascin expression in stage I non-small cell lung cancer. Korean. Tuberc Respir Dis 2008, 65:105-109.

54. Jung EJ, Lee JH, Min BW, Kim YS, Choi JS: Clinicopathologic significance of fascin, extracellular matrix metalloproteinase inducer, and ezrin expressions in colorectal adenocarcinoma. Indian J Pathol Microbiol 2011, 54:32-36.

55. Hashimoto Y, Shimada Y, Kawamura J, Yamasaki S, Imamura M: The prognostic relevance of fascin expression in human gastric carcinoma. Oncology 2004, 67:262-270.

56. Li $X$, Zheng H, Hara T, Takahashi H, Masuda S, Wang Z, Yang X, Guan Y, Takano $Y$ : Aberrant expression of cortactin and fascin are effective markers for pathogenesis, invasion, metastasis and prognosis of gastric carcinomas. Int J Oncol 2008, 33:69-79.

57. Tsai WC, Jin JS, Chang WK, Chan DC, Yeh MK, Cherng SC, Lin LF, Sheu LF, Chao YC: Association of cortactin and fascin-1 expression in gastric adenocarcinoma: Correlation with clinicopathological parameters. J Histochem Cytochem 2007, 55:955-962.
58. Zhao Q, Shen JH, Shen ZY, Wu ZY, Xu XE, Xie JJ, Wu JY, Huang Q, Lu XF, Li EM, Xu LY: Phosphorylation of fascin decreases the risk of poor survival in patients with esophageal squamous cell carcinoma. J Histochem Cytochem 2010, 58:979-988.

59. Hsu KF, Lin CK, Yu CP, Tzao C, Lee SC, Lee YY, Tsai WC, Jin JS: Cortactin fascin, and survivin expression associated with clinicopathological parameters in esophageal squamous cell carcinoma. Dis Esophagus 2009, 22:402-408.

60. Qin YR, Tang H, Qiao JJ, Li FF, Ai JY: Expression of fascin in human esophageal squamous cell carcinoma and its clinical significance. Nan Fang Yi Ke Da Xue Xue Bao 2011, 31:1216-1219.

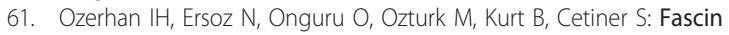
expression in colorectal carcinomas. Clinics 2010, 65:157-164.

62. Kim BG, Ha KW, Park JS, Yoo JH: Immunohistochemical studies of fascin MMP-9 overexpression, and proliferating index as prognostic factors in cases of a colon adenocarcinoma. Korean. J Korean Soc Coloproctol 2009, 25:393-400.

63. Pang $Q$, Zhang $X$, Zhang J, Li Y, Wu W, Wang H, Cui A, Zhang Y: Correlative studies on expression of CXCR4, CXCR12, Fascin and Ecadherin in colorectal carcinoma with lymphatic metastasis. Chinese. Chinese J Clin Oncol 2009, 36:926-929, 933.

64. Choi PJ, Yang DK, Son CH, Lee KE, Lee JI, Roh MS: Fascin immunoreactivity for preoperatively predicting lymph node metastases in peripheral adenocarcinoma of the lung $3 \mathrm{~cm}$ or less in diameter. Eur $J$ Cardiothorac Surg 2006, 30:538-542.

65. Zhao J, Zhou Y, Zhang Z, Tian F, Ma N, Liu T, Gu Z, Wang Y: Upregulated fascin1 in non-small cell lung cancer promotes the migration and invasiveness, but not proliferation. Cancer Lett 2010, 290:238-247.

66. Xue LY, Song YM, Tong T, Luo W, Dong LJ, Zou SM, Zheng S, Bi R, Zhan QM, Lu N: Expression of fascin and cytokeratin 14 in esophageal squamous cell carcinoma. Chinese. Zhonghua Yi Xue Za Zhi 2007, 87:2494-2498.

67. Begley CG, Ellis LM: Drug development: raise standards for preclinical cancer research. Nature 2012, 483:531-533.

68. Riley RD, Sauerbrei W, Altman DG: Prognostic markers in cancer: the evolution of evidence from single studies to meta-analysis, and beyond. Br J Cancer 2009, 100:1219-1229.

69. Sterne JA, Egger M, Smith GD: Systematic reviews in health care: investigating and dealing with publication and other biases in metaanalysis. BMJ 2001, 323:101-105.

70. Blot WJ: Esophageal cancer trends and risk factors. Semin Oncol 1994, 21:403-410.

71. Lundell LR: Etiology and risk factors for esophageal carcinoma. Dig Dis 2010, 28:641-644.

72. Brell M, Ibanez J, Tortosa A: O6-Methylguanine-DNA methyltransferase protein expression by immunohistochemistry in brain and non-brain systemic tumours: systematic review and meta-analysis of correlation with methylation-specific polymerase chain reaction. BMC Cancer 2011, 11:35.

73. Altman DG, Lausen B, Sauerbrei W, Schumacher M: Dangers of using "optimal" cutpoints in the evaluation of prognostic factors. J Natl Cancer Inst 1994, 86:829-835.

74. Smith RA, Tang J, Tudur-Smith C, Neoptolemos JP, Ghaneh P: Meta-analysis of immunohistochemical prognostic markers in resected pancreatic cancer. Br J Cancer 2011, 104:1440-1451.

75. Kayani B, Zacharakis E, Ahmed K, Hanna GB: Lymph node metastases and prognosis in oesophageal carcinoma-a systematic review. Eur J Surg Oncol 2011, 37:747-753.

76. Absi A, Adelstein DJ, Rice T: Esophageal Cancer. [http://www clevelandclinicmeded.com/medicalpubs/diseasemanagement/hematologyoncology/esophageal-cancer/].

77. Curtis C, Shah SP, Chin SF, Turashvili G, Rueda OM, Dunning MJ, Speed D, Lynch AG, Samarajiwa S, Yuan Y, Graf S, Ha G, Haffari G, Bashashati A, Russell R, McKinney S, Langerod A, Green A, Provenzano E, Wishart G, Pinder S, Watson P, Markowetz F, Murphy L, Ellis I, Purushotham A, Borresen-Dale AL, Brenton JD, Tavare $S$, Caldas $C$, et al: The genomic and transcriptomic architecture of 2,000 breast tumours reveals novel subgroups. Nature 2012, 486:346-352.

78. Asamura H, Goya T, Koshiishi Y, Sohara Y, Eguchi K, Mori M, Nakanishi Y, Tsuchiya R, Shimokata K, Inoue H, Nukiwa T, Miyaoka E: A Japanese Lung 
Cancer Registry study: prognosis of 13,010 resected lung cancers. J Thorac Oncol 2008, 3:46-52.

79. Kawase A, Yoshida J, Ishii G, Nakao M, Aokage K, Hishida T, Nishimura M, Nagai K: Differences between squamous cell carcinoma and adenocarcinoma of the lung: are adenocarcinoma and squamous cell carcinoma prognostically equal? Jpn J Clin Oncol 2012, 42:189-195.

80. Friedenberg F, Fernandez A, Sorondo B, Fazili J, Braitman L: The proximal shift in the distribution of colon cancer is independent of age and gender. J Appl Res Clin Exp Ther 2001, 1.

81. Rodel C, Sauer R: Radiotherapy and concurrent radiochemotherapy for rectal cancer. Surg Oncol 2004, 13:93-101.

82. Altman DG: Systematic reviews of evaluations of prognostic variables. BMJ 2001, 323:224-228.

\section{Pre-publication history}

The pre-publication history for this paper can be accessed here: http://www.biomedcentral.com/1741-7015/11/52/prepub

doi:10.1186/1741-7015-11-52

Cite this article as: Tan et al: Association of fascin-1 with mortality, disease progression and metastasis in carcinomas: a systematic review and meta-analysis. BMC Medicine 2013 11:52.

\section{Submit your next manuscript to BioMed Central} and take full advantage of:

- Convenient online submission

- Thorough peer review

- No space constraints or color figure charges

- Immediate publication on acceptance

- Inclusion in PubMed, CAS, Scopus and Google Scholar

- Research which is freely available for redistribution

Submit your manuscript at www.biomedcentral.com/submit 